DOI : 10.47828/jianaasian.v9i2.79

\title{
Kolaborasi Aktor Dalam Pelaksanaan Kebijakan Program Kota Tanpa Kumuh (Kotaku) di Kecamatan Kasemen Kota Serang
}

\author{
Vojana1, Delly Maulana², Rachmi Yulianti $^{3}$ \\ 1,2,3Program Studi Ilmu Administrasi Negara, Fakultas Ilmu Sosial, Ilmu Politik, dan Ilmu \\ Hukum, Universitas Serang Raya, Jalan Serang Cilegon Km 5 (Taman Drangong) Kota \\ Serang-Provinsi Banten
}

\section{ART I C LE IN F O}

\section{Article history:}

Received 11/11/2021

Received in revised form 18/12/2021

Accepted 30/12/2021

\begin{abstract}
The City Without Slums Program (KOTAKU) is one of the many strategic efforts of the Directorate General of Human Settlements, Ministry of Public Works and Public Housing to assist disaster management in Indonesia and support the "100-0-100 Movement", namely 100\% universal access to drinking water, $0 \%$ collection, and $100 \%$ access to proper sanitation. The general objective of this program is to increase access to basic infrastructure and services that are used to support livable, productive, and sustainable use. To achieve achievements in implementing the KOTAKU program, it is necessary to have cooperation or collaboration between the government, the community, and the private sector. Because the role of policy actors greatly determines success in policy formulation, policy implementation considers the consequences of the policies that have been made. Therefore, the purpose of this research is how the collaboration of the actors involved and the role of each actor is. The methodology used in this research is a qualitative method with a descriptive approach carried out through in-depth interviews, observation, and documentation. The results of this study indicate that this program has been implemented optimally, but the results have not been appropriately implemented. The actors who collaborate in the KOTAKU program are DisPERKIM, DPUPR, BAPPEDA, $B K M$, and the community.
\end{abstract}

Keywords: Actor Collaboration, Public Policy, KOTAKU Program

\begin{abstract}
Abstrak
Program Kota Tanpa Kumuh (KOTAKU) adalah satu dari sejumlah upaya strategis Direktorat Jenderal Cipta Karya Kementerian Pekerjaan Umum dan Perumahan Rakyat untuk mempercepat penanganan permukiman kumuh di Indonesia dan mendukung "Gerakan 100-0-100", yaitu 100\% akses universal air minum, $0 \%$ permukiman kumuh, dan 100\% akses sanitasi layak. Tujuan umum dari program ini adalah meningkatkan akses terhadap infrastruktur dan pelayanan dasar di permukiman kumuh perkotaan untuk mendukung perwujudan permukiman perkotaan yang layak huni, produktif, dan berkelanjutan. Demi tercapainya kelancaran dalam pelaksanaan kebijakan program KOTAKU maka perlu adanya kerjasama atau kolaborasi antara pemerintah, masyarakat, dan swasta. Karena peran aktor kebijakan sangat menentukan keberhasilan dalam perumusan kebijakan, implementasi kebijakan karena akan mempertimbangkan konsekuensi kebijakan yang telah dibuat. Oleh karena itu, tujuan dari penelitian ini adalah bagaimana kolaborasi aktor yang
\end{abstract}


terkait serta bagaimana peran masing-masing aktor tersebut. Metodologi yang digunakan dalam penelitian ini metode kualitatif dengan pendekatan deskriptif yang dilakukan melalui wawancara mendalam, observasi dan dokumentasi. Hasil dari penelitian ini menunjukkan bahwa program ini sudah terlaksana, tetapi hasil belum berjalan secara maksimal. Aktor yang berkolaborasi dalam program KOTAKU ini adalah DisPERKIM, DPUPR, BAPPEDA, BKM, dan masyarakat.

Kata kunci : Kolaborasi Aktor, Kebijakan Publik, Program KOTAKU

*)Vojana

E-mail : vojanaazwar98@gmail.com

\section{PENDAHULUAN}

Dalam Peraturan Pemerintah Republik Indonesia Nomor 66 Tahun 2014 Tentang Kesehatan Lingkungan pasal 1 ayat 1 , menjelaskan bahwa yang dimaksud dengan kesehatan lingkungan adalah upaya pencegahan penyakit dan/atau ganguan kesehatan dari faktor risiko lingkungan untuk mewujudkan kualitas lingkungan yang sehat, baik dari aspek fisik, kimia, biologi, maupun sosial, dan pada pasal 3 ayat 1 menjelaskan bahwa pemerintah, dalam hal ini pemerintah daerah provinsi, dan pemerintah daerah kabupaten/kota bertanggung jawab untuk menjamin tersedianya lingkungan yang sehat untuk mencapai derajat kesehatan yang setinggi-tingginya sesuai dengan kewenangannya (PP. RI Nomor 66, 2014). Oleh karena itu, salah satu perwujudan peran dari kebijakan pemerintah, hal ini dilihat dari peraturan pemerintah yang sudah dijelaskan sebelumnya, yakni mendirikan program Kota Tanpa Kumuh (KOTAKU).

Program Kota Tanpa Kumuh (KOTAKU) adalah satu dari sejumlah upaya strategis Direktorat Jenderal Cipta Karya Kementerian Pekerjaan Umum dan Perumahan Rakyat untuk mempercepat penanganan permukiman kumuh di Indonesia dan mendukung "Gerakan 100-0-100", yaitu $100 \%$ akses universal air minum, $0 \%$ permukiman kumuh, dan $100 \%$ akses sanitasi layak (Kotaku.pu.go.id, 2017). Tujuan umum dari program ini adalah meningkatkan akses terhadap infrastruktur dan pelayanan dasar di permukiman kumuh perkotaan untuk mendukung perwujudan permukiman perkotaan yang layak huni, produktif, dan berkelanjutan.

Dalam konteks Kota Serang, program Kota Tanpa Kumuh (KOTAKU) baru dimulai pada hari Rabu, tanggal 14 Agustus tahun 2019. Dalam pengerjaannya dilakukan secara serentak di 34 kelurahan. Program tersebut, tersebar di enam Kecamatan. (Serangkota.go.id, 2019). Program ini mengukuhkan 6 forum BKM perwakilan di setiap Kecamatan untuk melakukan proses pembentukan Kota Tanpa Kumuh (KOTAKU). Hasil observasi dan riset awal menunjukkan kecamatan terpantau sangat tidak layak, yaitu Kecamatan Kasemen, hal ini dikarenakan masih banyak rumah yang membutuhkan perbaikan atau harus direnovasi maupun jalanan yang harus di benahi untuk kedepannya. (Putri \& Rifki, 2019)

Demi tercapainya
dalam pelancaran
program KOTAKU makanananan perlu adanya
kerjasama atau kolaborasi antara


pemerintah, masyarakat, dan swasta. Karena peran aktor kebijakan sangat menentukan keberhasilan dalam perumusan kebijakan, implementasi kebijakan karena akan mempertimbangkan konsekuensi kebijakan yang telah dibuat.

Dalam program KOTAKU ada beberapa pihak stakeholders yang berkolaborasi, baik dari pihak pemerintah maupun dari masyarakatnya sendiri. Pihak yang berkolaborasi adalah Dinas Perumahan Rakyat dan Kawasan Permukiman (PERKIM), Dinas Pekerjaan Umum dan Penataan Ruang (DPUPR), Badan Perencanaan dan Pembangunan Daerah (BAPPEDA), Badan Keswadayaan Masyarakat (BKM), serta dari masyarakat dilingkungan itu sendiri.

Dari hasil pemetaan riset menunjukkan bahwa aktor yang berkolaborasi atau stakeholder yang terkait telah berperan besar terhadap program KOTAKU tersebut, meskipun pada faktanya proses serta hasil pelaksanaan kebijakan tersbut belum optimal. Tetapi setelah adanya program tersebut, masyarakat merasa sangat terbantu karena beberapa masalah yang dihadapi di lingkungan mereka dapat teratasi, meskipun masih ada saja masyarakat yang belum sadar betapa pentingnya menjaga kebersihan lingkungan. (Irawan, Alfitri, \& Saptawan, 2019; Purba \& Marom, 2016; Sulaiman, 2021)

Dari latar belakang di atas maka peneliti berfokus pada satu titik lokasi yang sudah terlaksananya program tersebut, yakni di Kampung Sampang 04 yang berada di kelurahan Terumbu, Kecamatan Kasemen Kota Serang. Dari hasil wawanacara terungkpan bahwa masyarakat mengaku sangat terbantu, karena masyarakat telah mendapatkan air bersih, serta dibangun beberaa fasilitas infrastruktur, seperti perbaikan jalan atau pemasangan paving block, MCK, sanitasi, dan drainase.

Namun dalam pelaksanaan pembangunan program KOTAKU pada kenyataannya belum berjalan dengan maksimal karena terdapat beberapa permasalahan, dimana rumah atau di lingkungan masyarakat sekitar sendiri yang mendapatkan program ini masih terlihat kumuh dan kurang adanya perawatan dari bangunan yang telah dibangun oleh pihak KOTAKU, atau melalui pola kerjasama dalam pelaksanaan program KOTAKU di Kecamatan Kasemen. Oleh karena itu, dalam artikel ini mencoba untuk melihat sejauhmana kolaborasi aktor dalam pelaksanaan kebijakan program Kota Tanpa Kumuh (Kotaku) di Kecamatan Kasemen Kota Serang.

\section{METODE PENELITIAN}

Metodologi yang digunakan dalam penelitian ini metode kualitatif yang dilakukan melalui wawancara, observasi dan dokumentasi. Dalam penentuan sumber data/informan yang diambil pada situasi sosial berdasarkan purposive sampling (pengambilan informan berdasarkan tujuan), maka yang akan menjadi informan adalah orang-orang yang menguasi atau memahami sesuatu melalui proses enkulturasi, sehingga sesuatu itu bukan sekedar diketahui, tetapi juga dihayati.

\section{HASIL DAN ANALISIS \\ Kolaborasi dalam Implementasi Program Kotaku}

Menurut Frederich, kebijakan adalah serangkaian konsep tindakan yang diusulkan oleh seorang atau 
sekelompok orang atau pemerintah dalam satu lingkungan tertentu dengan menunjukkan hambatanhambatan dan peluang, terhadap pelaksanaan usulan tersebut dalam rangka mencapai tujuan tertentu (Lubis, 2007; Pasolong, 2013)

Dari definisi di atas, dapat ditarik kesimpulan bahwa kebijakan publik merupakan keputusan yang dibuat dan diimplementasikan oleh pemerintah untuk memecahkan masalah publik sehingga dapat mencapai suatu tujuan yang diharapkan. Sementara itu, implementasi kebijakan menurut Ripley dan Franklin adalah apa yang terjadi setelah undang-undang ditetapkan yang memberikan otoritas program, kebijakan, keuntungan (benefit) atau sejenis keluaran yang nyata (tangible output) (Sulila, 2015:42).

\section{Implementasi kebijakan} merupakan salah satu tahap dari proses kebijakan setelah proses perumusan kebijakan publik. Proses implementasi merupakan tahapan yang sangat menentukan dalam proses kebijakan, apakah kebijakan tersebut berjalan dengan baik atau tidak. Bahkan, jika dipresentasikan implementasikan kebijakan memiliki presentase sekitar 60 persen, dan perumusan kebijakan dan evaluasi kebijakan sekitar 20 persen. Artinya, jika kebijakan yang dirumuskan sebaik apapun jikalau tidak diimplementasikan maka kebijakan tersebut hanya sebagai sebuah dokumen. (Maulana \& Nugroho, 2019)

Sementara itu, kolaborasi adalah proses dimana para aktor otonom atau seni-otonom berinteraksi melalui negosiasi formal maupun informal, secara bersama menciptakan aturan dan struktur yang mengatur hubungan mereka dan cara-cara untuk bertindak, atau memutuskan masalah yang membuat mereka bersama-sama. (Thomson, 2006)

Berdasarkan definisi tersebut, ada lima dimensi kunci kolaborasi sebagai berikut : Pertama, Governance (pemerintahan), yaitu para pihak yang berkolaborasi harus memahami bagaimana cara untuk bersama-sama membuat keputusan tentang aturan-aturan yang akan mengatur perilaku dan hubungan mereka; Kedua, Administration (administrasi), yaitu organisasi berkolaborasi karena mereka berniat untuk mencapai tujuan tertentu; Ketiga, Organization Autonomy (otonomi organisasi), yaitu dimensi ini menjelaskan dua dinamika potensial dan kekecewaan yang tersirat dalam upaya kolaboratif; Ketiga, Mutualisme (kebersamaan), yaitu kebersamaan berakar dari saling ketergantungan. Organisasi yang berkolaborasi harus saling berketergantungan pada hubungan yang saling menguntungkan didasarkan atas perbedaan kepentingan bersama; Keempat, Norms (norma), yaitu timbal balik dari kepercayaan, terkait erat secara konseptual. Dalam kolaborasi, organisasi yang berpartisipasi umumnya menunjukan sebuah "willif-you-will", didasarkan pada derajat mentalitas dan kewajiban timbal balik masing-masing.

Sedangkan ada beberapa instrumen dari kolaborasi actor, yaitu : Pertama, Face to Face Dialogue (dialog/tatap muka); dialog tatap muka antara para stakeholder. Pada tahap awal diperlukan dialog langsung antar stakeholder yang terlibat. Dialog langsung merupakan sebagai media komunikasi yang diperlukan bagi stakeholder untuk 
mengidentifikasi peluang, tantangan, kelemahan, dan keuntungan bersama yang ingin dicapai; Kedua, Trust Building (membangun kepercayaan); proses kolaboratif, bukan hanya tentang negosiasi tetapi juga tentang membangun kepercayaan antara stakeholder. Penggerak kolaborasi harus wajib membangun kepercayaan ditengah krisis atau kuatnya kepercayaan; Ketiga, Commitment to Process (komitmen bersama); berkaitan dengan saling ketergantungan, kepemilikan terhadap proses, dan keterbukaan untuk mengeksplorasi keuntungan bersama. Komitmen dan proses dinilai agar membangun keinginan atau niat melakukan perundingan mencapai tujuan yang diinginkan bersama; Keempat, Shared Understanding (pemahaman bersama); stakeholder harus mengembangkan pemahaman bersama tentang apa yang mereka bisa capai bersama secara kolektif. Pada tahapan ini, diperlukan pemahaman bersama untuk menyatukan persepsi terhadap substansi dan tujuan kolaborasi; Kelima, Intermedite Outcome (pencapaian hasil); indikator ini merupakan output sebagai hasil dari proses kolaboratif. Intermediate outcome dapat kembali ke dalam siklus proses kolaboratif, mendorong siklus yang baik untuk membangun kepercayaan dan komitmen. (Ansell, 2018)

Selanjutnya, berdasarkan surat edaran Jendral Cipta Kerja Nomor 40/SE/DC/2016 Tentang Pedoman Umum Program Kota Tanpa Kumuh (KOTAKU), program Kota Tanpa Kumuh (KOTAKU) adalah program yang menjadi platform atau basis penanganan kumuh yang mengintergrasikan berbagai sumber dan sumber perdanaan, termasuk dari pemerintah pusat, provinsi, Kota/Kabupaten, pihak donor, swasta, masyarakat, dan pemangku kepentingan lainnya (stakeholder) serta dari lembaga mitra pembangunan pemerintah (Direktorat Jenderal Cipta Karya, 2016).

\section{Kolaborasi Aktor dalam Pelaksanaan Kebijakan Program KOTAKU}

Memulai sebuah kerjasama dalam bentuk kolaborasi dibutuhkan arahan dan landasan berupa prinsip agar seluruh pihak yang terlibat memahami tanggungjawab dan perannya masing-masing. Kesepakatan yang telah dirancang dan disepakati berjalan sesuai dengan komitmen dan prinsip bersama, untuk itu diperlukan perhatian terhadap beberapa proses kolaborasi, yaitu sebagai berikut :

\section{Face to Face Dialogue (dialog/tatap muka)}

Dalam banyak aktor yang terlibat, demi mencapai tujuannya, tentunya para aktor harus membangun komunikasi dengan baik, agar terciptanya saling percaya, menghormati, dan saling berkomitmen. Dalam menciptakan hal tersebut para aktor melakukan dengan cara berdiskusi bersama mengenai pelaksanaan program KOTAKU tersebut. Dalam diskusi tersebut pasti ada saja pihak yang berbeda pendapat, cara meanangani hal tersebut biasanya para stakeholder berunding kembali sampai pada akhirnya menemukan titik terang, atau yang lebih mudah dipahami yaitu bermusyawarah. Dari pihak masyarakat sendiri tentunya sama, yaitu melakukan musayawarah atau rembug warga. 


\section{Trust Building (membangun kepercayaan)}

Dalam membangun kepercayaan terhadap stakeholder yang terlibat dalam program KOTAKU ini tentu merupakan salah satu hal yang paling penting, dikarenakan agar menghindari kesalahpahaman antara stakeholder satu dengan yang lainnya, sehingga untuk mencapai hasil tujuan yag ingin dicapai berjalan dengan semestinya.

Prinsip dari kolaborasi juga adanya kesetaraan, dan keterbukaan. Kolaborasi akan berjalan manakala dari semua pihak yang berkolaborasi saling percaya terhadap satu sama lain. Dari pihak KOTAKU sendiri selain pihak yang memfasilitasi program ini pihak KOTAKU tersebut mempunyai pendekatan-pendekatan yang bisa membangun kepercayaan kepada stakeholder, misalnya pendekatan secara individual, secara kelembagaan, maupun dituangkan dalam pertemuan resmi, atau menyelenggarakan forum, sehingga terjalinnya kolaborasi yang bertujuan untuk penuntasan wilayah kumuh tersebut.

\section{Commitment to Process (komitmen bersama)}

Cara untuk menjalin komitmen yang baik dengan para stakeholder mengenai program KOTAKU yaitu dengan membicarakan atau menyampaikan segala sesuatu apa yang sudah direncanakan, sehigga program tersebut terlaksana dengan baik.

Terjalinnya komitmen bersama dengan para stakeholder yaitu berupa kerjasama dalam membangun dan mencapai tujuan di dalam program KOTAKU. Dalam hal tersebut para stakeholder berusaha mengajak masyarakat untuk lebih memperhatikan mengenai kesehatan khususnya dalam hal kebersihan, dan juga tentunya lebih memfokuskan mengenai pembangunan infrastuktur, misalnya pembangunan jalan atau pemasangan paving block, drainase, sanitasi, serta MCK.

\section{Shared (pemahaman bersama)}

Metode dalam menyampaikan informasi terkait dalam program KOTAKU ini yaitu dengan diskusi atau membuat forum dengan para pihak stakeholder, rembug warga dan sosialisasi terhadap masyarakat lainnya, sosilisasi tersebut dilakukan tidak hanya satu kali melainkan beberapa kali agar informasi tentang program serta apa saja yang akan dilaksanakan, sehingga masyarakat diwilayah tersebut paham dan agar tidak adanya kesalahpahaman atau miss communication.

\section{Intermedite}

\section{(pencapaian hasil)}

Outcome

Dalam pencapaian hasil pelaksanan program KOTAKU, khususnya di wilayah Kampung Sampang 04, Kelurahan Terumbu, memiliki hasil yang baik, karena hasil dari pelaksanaan tersebut masyarakat di wilayah tersebut merasakan manfaat yang sangat membantu dikehidupan mereka. Pelaksanan program KOTAKU selain pihak pemerintah, tidak terlepas juga dari dukungan serta kerjasama dari masyarakat.Akan tetapi setelah selesainya pembangunan tersebut, masih ada saja masyarakat yang kurang peduli terhadap kebersihan lingkungan. Masyarakat masih ada saja yang membuang sampah sembarangan, sehingga masih banyak sampah yang berserakan di lingkungan tersebut. Terkait dari hasil semua bangunan atau fasilitas yang sudah dibangun oleh pihak 
program KOTAKU, masyarakat tersebut mencoba berusaha untuk mempercantik fasilitas yang telah dibangun, misalnya bangunan MCK yang ditanami dengan tumbuhan atau bunga-bunga hias yang diletakkan dibeberapa bagian depan dan samping bangunan tersebut.

\section{Peran Masing-masing Aktor dalam Pelaksanaan Kebijakan Program KOTAKU}

\section{A. Dinas Perumahan Rakyat dan Kawasan (PERKIM) Permukiman}

Tugas atau peran dari Dinas PERKIM sendiri semuanya telah diatur berdasarkan Peraturan Gubernur Banten Nomor 83 Tahun 2016 Tentang Kedudukan, Tugas Pokok, Fungsi, Tipe, Susunan Organisasi dan Tata Kerja Perangkat Daerah Provinsi Banten. Dalam Dinas PERKIM terdiri atas 1 (sekretariat) dan 3 (tiga) bidang, yaitu bidang perumahan, bidang permukiman, dan ada satu bidang yang terbaru yaitu bidang pertanahan, yang dimana bidang pertanahan ini awalnya berada di atas tugas DPUPR. Dalam kebijakan program KOTAKU, pihak dari Dinas PERKIM dalam tupoksinya berperan atau bertugas untuk menangani pencegahan dan pengendalian kawasan kumuh serta menangani kawasan non-kumuh. Pihak PERKIM mempunyai program kegiatan yang sudah disiapkan dalam proses perencanaanya (Peraturan Gubernur Banten, 2016).

Mengenai program KOTAKU ini Dinas PERKIM mempunyai tugas atau tupoksi dalam pembuatan pembangunan atau infrastruktur, khususnya di wilayah Kelurahan Terumbu Kampung Sampang 04, seperti pembangunan jalan yang rusak dengan memasangkan paving block agar terlihat rapih dan bersih, selain itu agar di lingkungan tersebut tidak mudah tergenang air saat hujan yang menimbulkan lumpur di kawasan tersebut.

Pembuatan drainase juga dilakukan oleh pihak Dinas PERKIM, drainase merupakan jenis infrastruktur yang sangat dibutuhkan terutama di daerah perkotaan untuk mendukung terciptanya sistem sanitasi yang bersih, sehat, dan nyaman untuk lingkungan sekitar. Drainase berguna untuk proses pengaliran, menguras, membuag air atau mengeringkan suatu area dari genangan air, sehingga drainase berguna untuk mencegah terjadinya banjir. Drainase juga berguna untuk mengontrol kualitas air tanah pada suatu wilayah.

Setelah selesainya pembangunan infrastruktur yang dilakukan oleh program KOTAKU tersebut, masyarakat di Kampung Sampang 04 sangat senang dan terbantu karena kesulitan atau kendala yang dialami sudah bisa teratasi, meskipun ada saja masyarakat yang belum sadar betapa pentingnya menjaga kebersihkan lingkungan, khususnya di lingkungan tempat mereka tinggal.

\section{B. Dinas Pekerjaan Umum dan Penataan Ruang (DPUPR) Kota Serang}

Peran DPUPR terhadap pelaksanaan kebijakan program KOTAKU ini, khususnya di kampung Sampang 04 Kelurahan Terumbu yaitu berperan sebagai aktor yang melakukan pembuatan sanitasi dan termasuk juga pembangunan MCK. Sanitasi tersebut merupakan salah satu faktor bagaimana keadaan kesehatan suatu lingkungan yang mencakup perumahan, pembuangan kotoran, penyediaan air bersih dan sebagainya. Sanitasi juga dapat diartikan sebagai kegiatan yang 
ditujukan untuk meningkatkan standar kondisi lingkungan yang mendasar, yang mempengaruhi kesehatan masyarakat di wilayahnya.

Dinas PUPR juga berperan juga sebagai koordinator mengenai pembangunan MCK. Dalam proses pembangunan tersebut, yang mengerjakan pembangunan yaitu para petukang yang dikoordinasi oleh ketua BKM serta pihak masyarakat lainnya yang terlibat. Sebelum adanya bangunan MCK tersebut, masih banyak masyarakat yang merasakan kesulitan untuk mandi, atau membuang air besar karena belum mempunyai kamar mandi sendiri di rumahnya. Biasanya masyarakat yang belum mempunyai kamar mandi di rumahnya, masyarakat melakukan untuk membersihkan badan atau mandi, membuang air besar atau mencuci pakaian dilakukan di sekitar sungai atau kali yang berada dekat dengan rumah masyarakat.

\section{Badan Perencanaan dan Pembangunan Daerah (BAPPEDA) Kota Serang}

Dalam mendukung mendukung pencapaian target Sustainable Development Goals (SDGs) dalam menyelesaikan permasalahan permukiman Kota Serang, khususnya di Kelurahan Terumbu, tepatnya di Kampung Sampang 04, BAPPEDA Kota Serang dalam bidang infrastruktur dan kewilayahan menyelenggarakan rapat koordinasi kegiatan Infrastructure Livelihood dengan OPD atau stakeholder terkait sebelum terlaksananya kebijakan program KOTAKU tersebut.

Peran atau tupoksi dari BAPPEDA untuk program KOTAKU ini yaitu sebagai pendamping atau pengawal dari perencanaanperencanaan dari program tersebut, seperti target dan apa yang ingin dicapai, serta anggarannya. Tetapi perencanaan tersebut tetap tugas dari pihak stakeholder yang lainnya. Bisa dikatakan bahwa, peran BAPPEDA sendiri yaitu badan yang mengkoordinasikan stakeholder yang terlibat.

\section{Badan \\ Keswadayaan Masyarakat (BKM) Kelurahan Terumbu}

Pihak dari BKM terhadap program KOTAKU ini yaitu sebagai penggerak masyarakat terhadap terlaksananya program di wilayah tersebut. Sebelum terlaksananya program tersebut tentu BKM sendiri membuat forum diskusi serta rembug warga yang bertujuan agar tercapainya satu suara. Musyawarah tersebut dilakukan unutuk mengantisipasi agar tidak terjadinya kesalahpahaman antara penyelenggara terhadap warganya sendiri. Pihak BKM juga sebagai pihak yang menerima anggaran untuk program KOTAKU tersebut.

\section{KESIMPULAN}

Berdasarkan hasil analisis peneliti mengenai kolaborasi aktor dalam pelaksanaan kebijakan program Kota Tanpa Kumuh (KOTAKU) ini berjalan dengan lancar, dimana pihak yang berkolaborasi atau stakeholder yang terkait telah berperan besar terhadap program Kota Tanpa Kumuh (KOTAKU) khususnya dalam penelitian ini peneliti berfokus pada wilayah Kecamatan Kasemen, Kelurahan Terumbu, Kampung Sampang 04.

Ada bebarapa aktor khusus yang berkolaborasi pada program KOTAKU tersebut, baik dari pihak pemerintah maupun pihak dari masyarakatnya sendiri. Pihak dari pemerintah sendiri yaitu, Dinas Perumahan Rakyat dan Kawasan Permukiman Kota Serang, Dinas Pekerjaan Umum 
dan Penataan Ruang Kota Serang, Badan Perencanaan dan Pembangunan Daerah Kota Serang. Pihak dari masyarakatnya sendiri seperti Badan Keswadayaan Masyarakat, termasuk RT dan RW, serta masyarakat di wilayah tersebut.

Dalam hasil pelaksanaan program KOTAKU ini berdampak besar kepada masyarakat, mereka sangat terbantu setelah adanya program KOTAKU ini. Meskipun masih adanya masyarakat yang belum sadar akan kebersihan. Dan dari pihak BKM sendiri kurang mengawasi keadaan bangunan, dan dari pihak masyarakatnya kurang merawat fasilitas yang telah dibangun oleh pihak program KOTAKU.

Saran bagi aktor atau stakeholder yang berkolaborasi dalam pelaksanaan kebijakan program Kota Tanpa Kumuh (KOTAKU), yaitu: (1) Pihak yang berkolaborasi pada program KOTAKU ini alangkah baiknya meningkatkan kerjasama dalam hal kominikasi dan koordinasi, sehingga kedepannya program tersebut akan berjalan lebih baik lagi; (2) Seharusnya pihak BKM sendiri lebih mengawasi atau mengontrol semua bangunan atau fasilitas yang telah dibangun oleh program KOTAKU, seperti pembangunan jalan atau pemasangan paving block, drainase, sanitasi, serta MCK; dan (3) Masyarakat sebaiknya lebih sadar dan menjaga akan pentingnya kesehatan, khususnya mengenai kebersihan lingkungan.

\section{REFERENSI}

Ansell, C. (2018). Collaborative platforms as a governance strategy. Journal of Public Administration Research and
Theory, 28(1), 16-32. https://doi.org/10.1093/jopart/ mux030

Direktorat Jenderal Cipta Karya. (2016). Surat Edaran Jendral Cipta Kerja Nomor 40/SE/DC/2016 Tentang Pedoman Umum Program Kota Tanpa Kumuh (KOTAKU).

Irawan, P., Alfitri, \& Saptawan, A. (2019). Jaringan Aktor Dalam Pemberdayaan Masyarakat Pada Program Kota Tanpa Kumuh (KOTAKU) Di Kelurahan Pasar II Kecamatan Prabumulih Utara Kota Prabumulih Provinsi Sumatera Selatan. Jurnal Empirika, 4(1), 1-18. https://doi.org/10.47753/je.v4i 1.70

Kotaku.pu.go.id. (2017). Tentang Program Tanpa Kumuh (Kotaku).

Lubis, S. (2007). Kebijakan Publik, Teori \& Praktik. Bandung: CV. Mandar Maju.

Maulana, D., \& Nugroho, A. (2019). KEBIJAKAN PUBLIK (Cara Mudah Memahami Kebijakan Publik). Serang: CV. AA. Rizky.

Pasolong, H. (2013). Kepemimpinan Birokrasi. Bandung: Alfabeta.

Peraturan Gubernur Banten. (2016). Peraturan Gubernur Banten Nomor 83 Tahun 2016 Tentang Kedudukan, Tugas Pokok, Fungsi, Tipe, Susunan Organisasi dan Tata Kerja Perangkat Daerah Provinsi Banten.

Purba, J. E. A., \& Marom, A. (2016). Analisis Peran Aktor Dalam Implementasi Program Kotaku (Kota Tanpa Kumuh) di Kelurahan Bandarharjo Semarang Utara, Kota Semarang. 
Journal of Public Policy And Management Review, 10(2), 119.

https://doi.org/10.14710/jppmr .v10i2.30682

Putri, R., \& Rifki. (2019). Program Kotaku Diprioritaskan di Kasemen.

Republik Indonesia. (2014). Peraturan Pemerintah Republik Indonesia Nomor 66 Tahun 2014 Tentang Kesehatan Lingkungan.

Serangkota.go.id. (2019). Pembentukkan Kota Tanpa Kumuh KOTAKU.

Sulaiman, A. L. (2021). Proses Kolaborasi Penanganan Permukiman Kumuh Melalui Program Kota Tanpa Kumuh (Kotaku) di Kota Bandung (Studi Kasus: Kelurahan Tamansari Kecamatan Bandung Wetan). Majalah Media Perencana, 2(1), 1-23.

Sulila, I. (2015). Implementasi Dimensi Pelayanan Publik dalam Konteks Otonomi Daerah. Sleman: Deepublish.

Thomson, A. M. (2006). Collaboration processes: Inside the black box. Public Administration Review. https://doi.org/10.1111/j.15406210.2006.00663.x 